\title{
Preliminary results of thermal comfort analysis in selected buildings
}

\author{
Grzegorz Majewski ${ }^{1, *}$, Marek Telejko ${ }^{1}$, and Lukasz J. Orman ${ }^{1}$ \\ ${ }^{1}$ Kielce University of Technology, al. Tysiąclecia Państwa Polskiego 7, Kielce 25-314, Poland
}

\begin{abstract}
The paper analyses thermal comfort in an intelligent building. Intelligent buildings are now widely seen both in Poland and abroad as a result of developments in engineering sciences. However, data on the thermal comfort provided in the buildings are limited. The research described in this paper was carried out in ENERGIS intelligent building of the Kielce University of Technology. The parameters measured included air temperature, relative air humidity, air flow rate and carbon dioxide concentration. Average radiation temperature was determined. The key element was the study of thermal sensation in occupants present at the time of the measurements. The studies were performed in classrooms during the class. The students completed a questionnaire at the beginning and end of the class. The persons present in the classrooms evaluated their thermal sensations using a seven-level thermal comfort scale. The questionnaire included such questions as the type of clothing and the degree of physical activity of the people sitting in the classroom. On the basis of the measurements of classroom microclimate parameters, PMV (Predicted Mean Vote) and PPD (Predicted Percentage Dissatisfied) indices were determined. The responses from the questionnaires provided actual average assessment of thermal sensation and actual percentage of dissatisfied people.
\end{abstract}

\section{Introduction}

Thermal comfort is one of the climatic elements with variable parameters such as air temperature, air humidity, relative air flow rate, mean radiant temperature, thermal insulation of clothing and physical activity. The study of thermal comfort began in the 20th century when microclimate in buildings could be controlled. This would not have been possible without the development of thermodynamics in the 19th century, which markedly contributed to the growth of thermal control technology. The discoveries of two scientists, Richard Mollier, regarded as the precursor of thermodynamic calculations, and Willis Carrier, the creator of modern air conditioning, gave rise to a new discipline referred to as thermal comfort. The interdisciplinary aspect of thermal comfort is reflected in physical, psychological, physiological, social and cultural factors that have to be considered, along with clothing type, eating habits, climate and building types. One of the first scientists to study thermal comfort was Bedford, who in 1936 proposed a seven-point scale of thermal

* Corresponding author: majewskigrzegorz@,wp.pl 
sensations [1]. Other researchers of that time, such as Winslow, Herrington and Gagge [2], also focused their professional interests on thermal comfort issues. In 1957 Yaglou and Minard [3] developed the Wet Bulb Globe Temperature (WBGT) indicator to evaluate average effect of temperature on a human being in the period representative of the nature of his or her work. In the sixties and seventies of the $20^{\text {th }}$ century, L. O. Fanger published the thermal comfort equation and PMV (Predicted Mean Vote) and PPD (Predicted Percentage Dissatisfied) indices $[4,5]$. These indices continue to apply as recommended by, for example, PN-EN ISO 7730 [6].

The current standards defining the mean vote (PMV) and the percentage of dissatisfied persons (PPD) include the European standard PN-EN 15251 [7] and the American ASHRAE Standard 55-2013 [8]. A very large amount of research is being conducted worldwide on thermal comfort of occupants of various buildings in which many people are gathered at the same room at the same time. In [9] Ricciardi and Buratti reported the result from their investigations carried out in a theatre building. Fabbri [10] studied thermal comfort in a kindergarten. This paper focuses on studying thermal comfort of occupants of teaching rooms in the building of the Faculty of Environmental, Geomatic and Energy Engineering at the Kielce University of Technology. Actual thermal sensations obtained from the occupants were compared with the PMV and PPD indicators. The studies of thermal comfort in classrooms have been conducted in many parts of the world. M. A. Nico, S. Liuzzi and P. Stefanizzi [11] investigated thermal comfort of students in university classrooms and compared the sensations reported by men and women. The results indicate that female students are more sensitive to cold and tend to wear thicker clothes. Cao et al. [12] studied thermal comfort in classrooms at universities in three Chinese cities representing different climatic zones: Harbin as the coldest city, Beijing with a little higher temperature and Shanghai with the highest temperatures. In Hrabin, more than $70 \%$ of data fell in comfortable zone. In Shanghai, more than $80 \%$ of data were in the winter comfortable zone. The percentage of people satisfied with the cold conditions in Beijing was lower than those in Hrabin and Shanghai. Abdallach [13] demonstrated that at the indoor temperature higher than $28^{\circ} \mathrm{C}$, the PMV indicator is lower than $90 \%$, and the PPD indicator is greater than $10 \%$ in particular in Muslim female students with covered heads. The study revealed that $83 \%$ of students surveyed prefers cooler air temperatures. Similar investigations were conducted by O'Donovan et al [14] and Katafygiotou and Serghides [15].

\section{Research procedure}

The studies were carried out in the ENERGIS building occupied by the Faculty of Environmental, Geomatic and Energy Engineering at the Kielce University of Technology. An indoor air quality monitor, an anemometer and a pyrometer were used to measure microclimate parameters such as air temperature, air flow rate, temperature of the walls surrounding the rooms and carbon dioxide concentration. Measurement results were recorded at 5 minute intervals. The microclimate parameters were measured at $130 \mathrm{~cm}$, that is at the height of a sitting person's head. The temperature of the walls was measured at the beginning and at the end of the classes. A $1 \mathrm{~m}$ spacing was maintained for wall temperature measurements carried out at the height of $130 \mathrm{~cm}$. Temperatures of the floor and ceiling were also recorded. The assessment of thermal comfort was performed through anonymous questionnaires in which the students evaluated their thermal sensations on a seven-point thermal comfort scale. A total of 101 students in three classrooms participated in the survey by filling in the questionnaires at the beginning and at the end of the classes. The studies were conducted in summer. Test no. 1 was performed in a lecture hall with a net area of $93.13 \mathrm{~m}^{2}$ on 20 June 2016 between 13:35 and 14:20. Test no. 2 was 
performed in the lecture hall with a net area of $157.03 \mathrm{~m}^{2}$ located on the western side on 28 June 2016 between 10:00 and 11:20. Test no. 3 was performed in the lecture hall located on the eastern side, of $53.14 \mathrm{~m}^{2}$ net area on 4 July 2016 between 13:00 and 14:45. Mechanical ventilation and air conditioning were on during the tests.

\section{Test results and comparison to existing models}

\subsection{Test results}

The indoor parameters are shown in Table 1. All the occupants were assumed to have metabolic rate at 1.2 met $\left(70 \mathrm{~W} / \mathrm{m}^{2}\right)$. The questionnaire results indicated that thermal insulation of clothing in all the respondents was $\mathrm{I}_{\mathrm{cl}}=0.50$ clo $\left(0.080 \mathrm{~m}^{2} \mathrm{KW}\right)$. Test no. 1 showed carbon dioxide concentration twice as high as that recorded during tests no. 2 and no. 3. This result is associated with different numbers of occupants present during the tests. Sixty people were present in the room during the Test no. 1, with 25 people occupying the room in Test no. 2 and 16 people in Test no. 3. Indoor air temperatures at the beginning of the tests were higher than those at the end of the tests. During the class the air conditioner was switched on, which lowered the air temperature. In the break between the classes, the air conditioner was switched off, allowing the temperature to rise. The value of the air temperature at the beginning of the class was recorded prior to switching on the air conditioner.

Table 1. Summary of microclimate parameters in three university classrooms.

\begin{tabular}{|c|c|c|c|c|c|}
\hline $\begin{array}{c}\text { At the } \\
\text { beginning } \\
\text { of class/ At } \\
\text { the end } \\
\text { of class } \\
\end{array}$ & $\begin{array}{c}\text { Outdoor } \\
\text { temperature } \\
{\left[{ }^{\circ} \mathrm{C}\right]}\end{array}$ & $\begin{array}{c}\text { Indoor } \\
\text { temperature } \\
{\left[{ }^{\circ} \mathrm{C}\right]}\end{array}$ & $\begin{array}{c}\text { Indoor } \\
\text { temperature } \\
\text { relative } \\
\text { humidity } \\
{[\%]} \\
\end{array}$ & $\begin{array}{l}\text { Indoor } \\
\text { air flow } \\
\text { rate } \\
{[\mathrm{m} / \mathrm{s}]} \\
\end{array}$ & $\begin{array}{c}\text { Indoor carbon } \\
\text { dioxide } \\
\text { concentration } \\
\text { [ppm] }\end{array}$ \\
\hline \multicolumn{6}{|c|}{ TEST NO 1 (Classroom 1) } \\
\hline $\begin{array}{l}\text { At the } \\
\text { beginning } \\
\text { of class }\end{array}$ & 23.0 & 25.9 & 65.8 & 0.15 & 1194 \\
\hline $\begin{array}{l}\text { At the end } \\
\text { of class }\end{array}$ & 23.0 & 25.1 & 56.7 & 0.15 & 2128 \\
\hline \multicolumn{6}{|c|}{ TEST NO 2 (Classroom 2) } \\
\hline $\begin{array}{c}\text { At the } \\
\text { beginning } \\
\text { of class }\end{array}$ & 22.0 & 29.2 & 51.3 & 0.12 & 477 \\
\hline $\begin{array}{l}\text { At the end } \\
\text { of class }\end{array}$ & 22.0 & 28.3 & 49.9 & 0.08 & 678 \\
\hline \multicolumn{6}{|c|}{ TEST NO 3 (Classroom 3) } \\
\hline $\begin{array}{l}\text { At the } \\
\text { beginning } \\
\text { of class }\end{array}$ & 23.0 & 29.6 & 39.2 & 0.09 & 479 \\
\hline $\begin{array}{l}\text { At the end } \\
\text { of class }\end{array}$ & 23.0 & 28.4 & 43.2 & 0.12 & 731 \\
\hline
\end{tabular}

Figure 1 shows actual mean thermal sensations of the students at the beginning and end of the classes. Assessments of their thermal sensations varied with the time of assessment. 
In test 1 , at the air temperature above $25^{\circ} \mathrm{C}$ thermal sensations decreased at the end of the class, whereas in tests 2 and 3 , at $28-29^{\circ} \mathrm{C}$, the sensations increased.

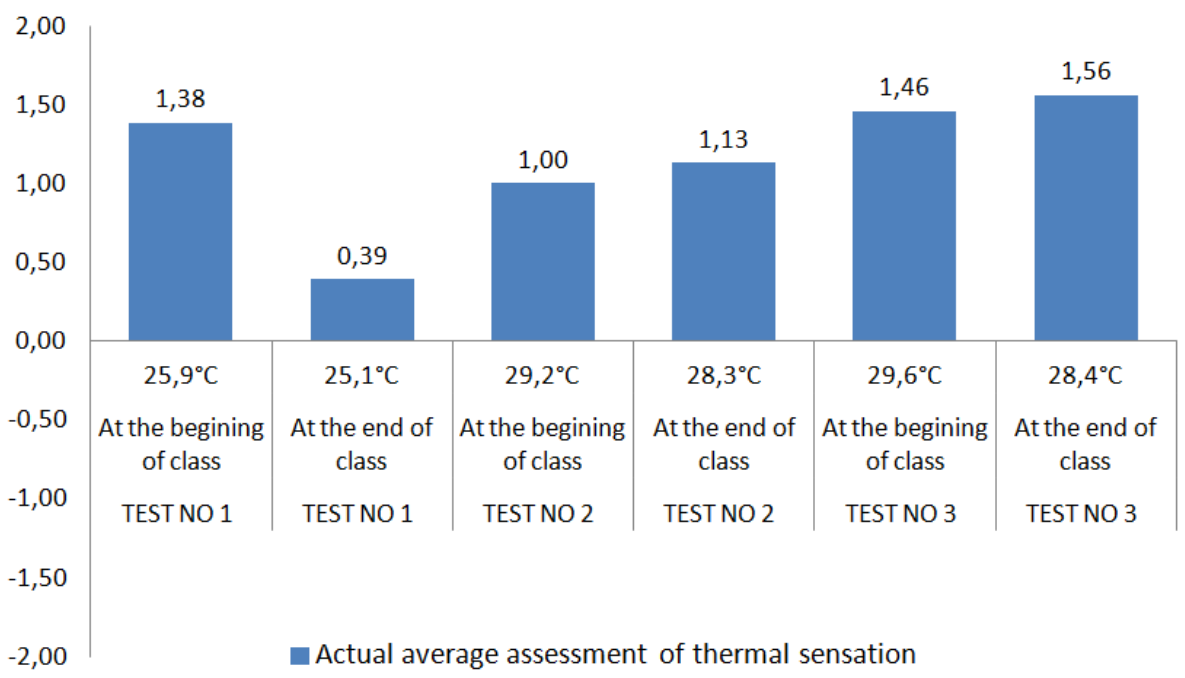

Fig. 1. Real mean assessment of thermal sensations of respondents at the beginning and at the end of class.

Figure 2 shows the change in the percentage of dissatisfied students at the end of class compared with their sensations at the beginning of class. As in chart 1, at air temperature above $25^{\circ} \mathrm{C}$, the percentage of students dissatisfied at the end of class decreased. In tests 2 and 3 , at $28-29^{\circ} \mathrm{C}$ the percentage of dissatisfied students increased relative to the beginning of class.

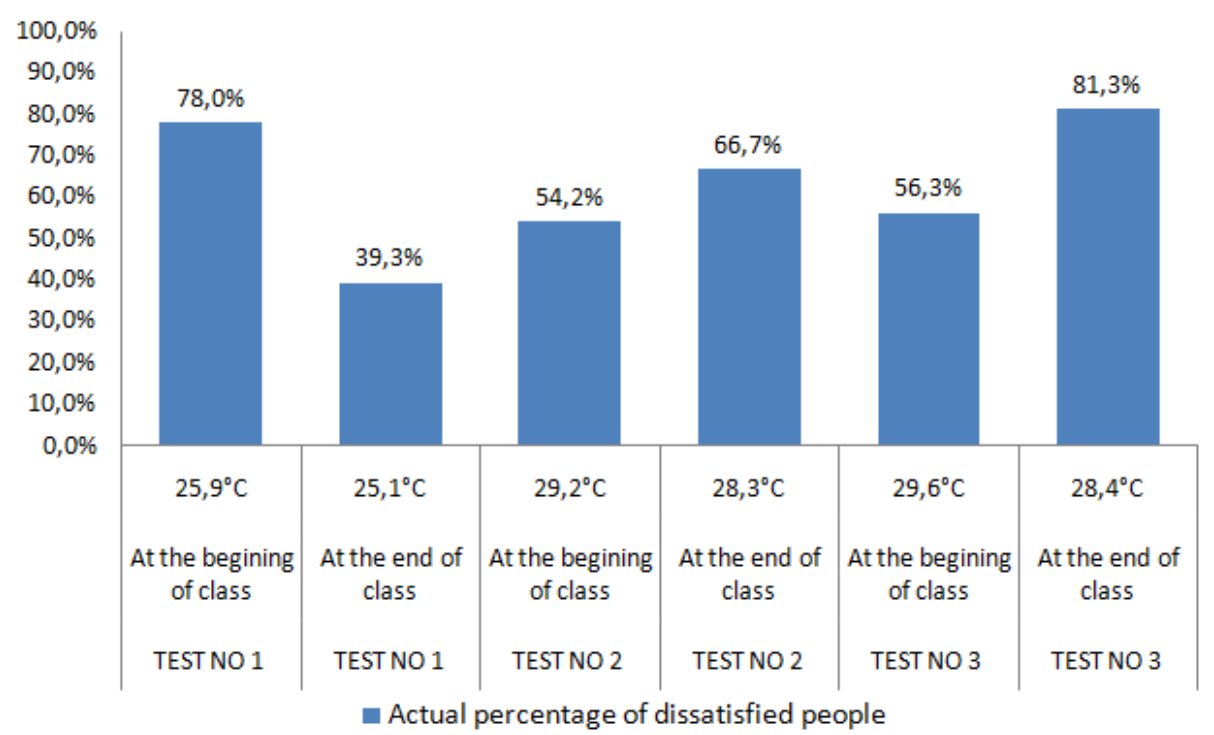

Fig. 2. Real percentage of respondents dissatisfied with their thermal sensations at the beginning and end of class. 
Figure 3 compares mean sensations of female and male students. In most cases, the female students were more sensitive to temperature than men. The reverse situation occurred in one case only.

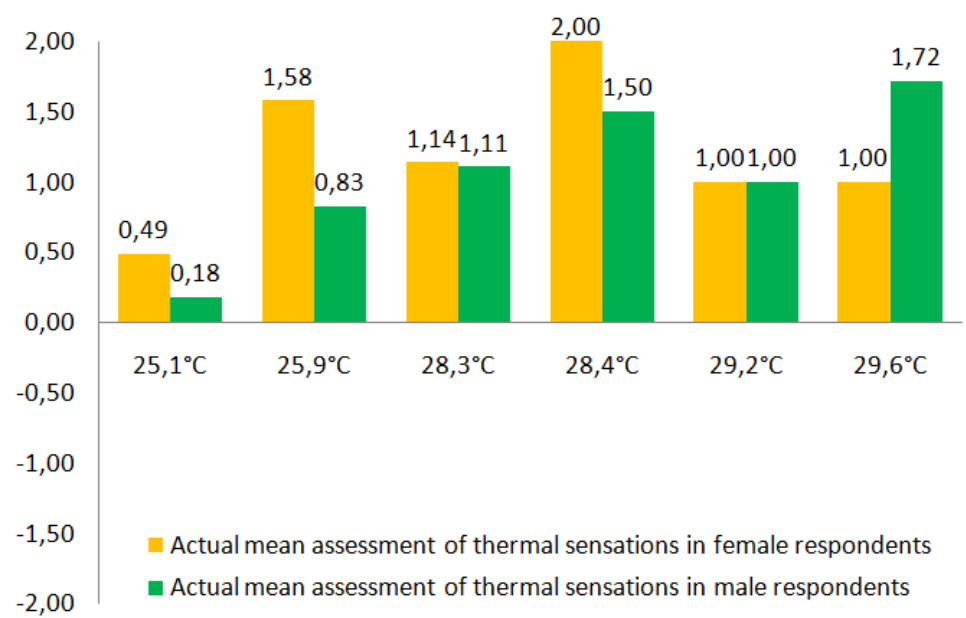

Fig. 3. Actual sensations of female respondents versus those of male respondents.

Figure 4 compares the percentage of dissatisfied female and male students. In the majority of cases, the female students were more dissatisfied with thermal conditions in the rooms.

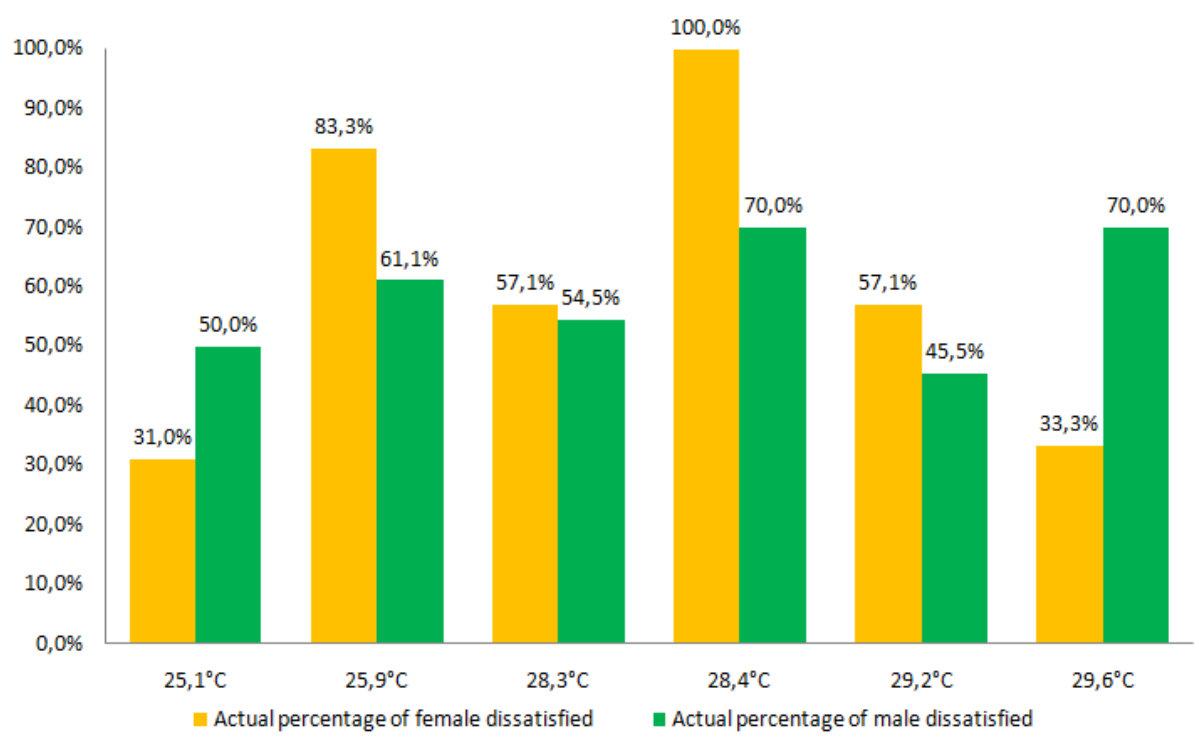

Fig. 4. Percentage of dissatisfied female respondents versus dissatisfied male respondents.

\subsection{Comparison of the results to available models}

Figure 5 compares the PMV indicator according to ASHRAE-55-2013 and EN-15251 with the actual mean assessment of thermal sensations from the study. It follows from the figure that in most cases the actual mean assessment of thermal sensations is markedly 
higher than that obtained from the calculation of PMV in compliance with the two standards. Only in one case the assessment of thermal sensations was lower than the PMV.

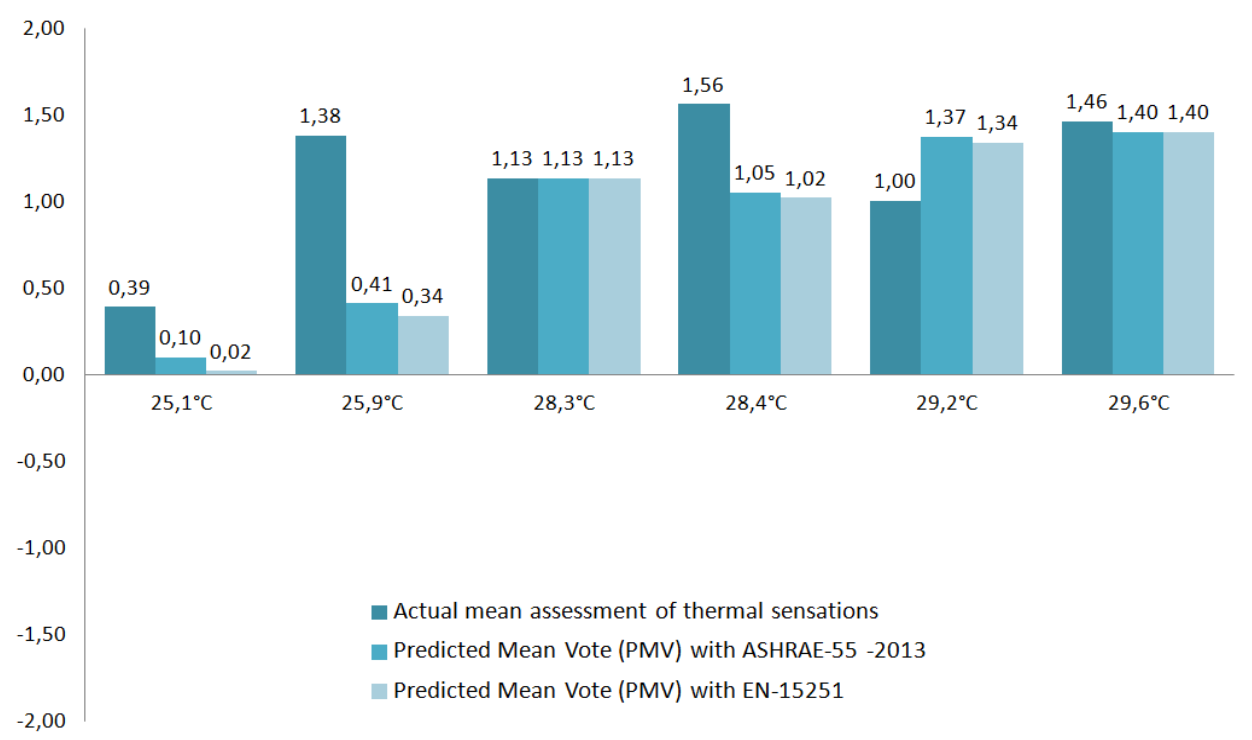

Fig. 5. The PMV depending on ambient temperature according to ASHRAE-55-2013 and EN-15251 versus actual mean assessment of thermal sensations.

Figure 6 shows a comparison of the PPD according to ASHRAE-55-2013 and EN15251 with the actual percentage of dissatisfied people found during the study. A markedly higher actual percentage of dissatisfied people was found than that shown by the PPD indicator calculated according to the American and European standards.

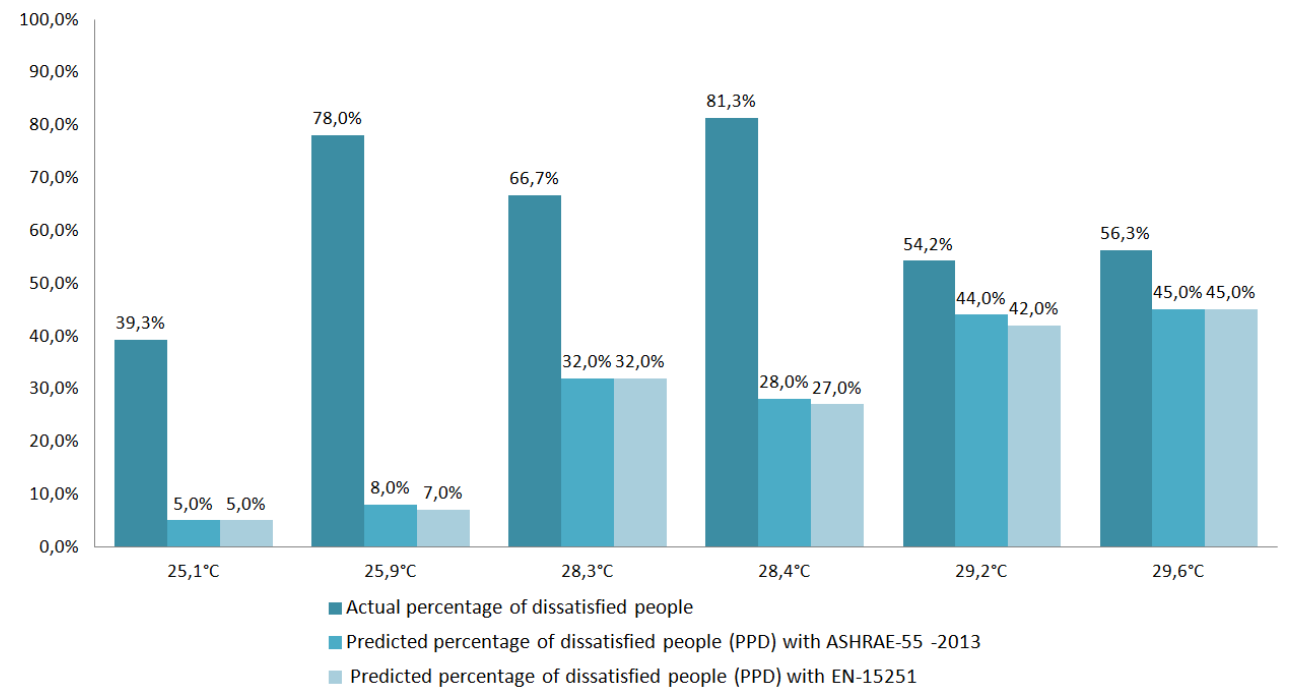

Fig. 6. The PPD depending on ambient temperature according to ASHRAE-55-2013 and EN-15251 versus the actual percentage of dissatisfied respondents. 


\section{Conclusions}

The study indicates that most occupants of the classrooms (39-81\%) are dissatisfied with their thermal sensations. According to the results obtained, female respondent were more than male respondents dissatisfied with the thermal conditions in the classrooms. The experimental results were compared to the PMV and PPD indices commonly used in compliance with ASHRAE-55-2013 and EN-15251. Substantial differences were observed between the thermal comfort indices and the actual assessment derived from the people present in the classrooms. Despite technological advancement of intelligent buildings, a high percentage of people was dissatisfied with the thermal conditions in the building. In view of the above, to provide optimal thermal comfort conditions, it seems expedient to modify the thermal sensation indices in buildings and to develop operating guidelines for the control of heating, ventilation and air conditioning systems.

\section{References}

1. T. Bedford, Ind. Heal. Res. Board, 76 (1936)

2. C.-E. A. Winslow, L. P. Herrington, A. P. Gagge, Pierce J. B., Laboratory of Hygiene, New Haven, 16, 288-299 (1937)

3. C. P. Yaglou, D. Minard, Am. Med. Ass. Arch. Ind. Hlt., 16, 302-316 (1957)

4. P. O. Fanger, ASHRAE Trans, 73, 1-4 (1967)

5. P. O. Fanger, Thermal comfort-analysis and applications in environmental engineering, (Danish Technical Press, Copenhagen 1970)

6. EN ISO 7730, 2005. Ergonomics of the thermal environment - Analytical determination and interpretation of thermal comfort using calculation of the PMV and PPD indices and local thermal comfort criteria, Inter. Stand. Org. (2005)

7. PN-EN 15251, 2007. Indoor Environmental input parameters for design and assessment of energy performance of buildings addressing indoor air quality, thermal environment, lighting and acoustics, Inter. Stand. Org. (2007)

8. ASHRAE Standard 55-2013 Thermal Environmental Conditions for Human Occupancy (2013)

9. P. Ricciardi, C. Buratti, Energ. and Build. 99, 243-252 (2015)

10. K. Fabbri, Build. and Envir. 68, 202-214 (2013)

11. M. A. Nico, S. Liuzzi, P. Stefanizzi, Appl. Ergon., 48, 111-120 (2015)

12. B. Cao, M. Luo, M. Li, Y. Zhu, Energ. and Build. 133, 469-477 (2016)

13. A. S. H. Abdallach, Proc. Engin. 121, 1674-1681 (2015)

14. A. O’Donovan, P. D. O'Sullivan, M. D. Murphy, Energ. and Biuld. 135, 312-323 (2017)

15. M. C. Katafygiotou, D. K. Serghides, Sustain. Cit. and Soc., 13, 303-312 (2014) 